\title{
Um Estudo de Caso sobre as Implicações da Abordagem Ausubeliana no Ensino de Física
}

\author{
A Study of Case on the Implications of Ausubelian Approach in the Physics Teaching
}

\author{
Samuel Nunes de Santana* e Elder Sales Teixeira ${ }^{\dagger}$ \\ Departamento de Física - UEFS \\ Campus Universitário, Km 03, BR 116 \\ Feira de Santana - BA - 44031-460 \\ Programa de Pesquisa e Pós-Graduação em Ensino, \\ Filosofia e História das Ciências - UFBA-UEFS
}

\begin{abstract}
Este trabalho fundamenta-se na pesquisa ação utilizada para investigar o processo de aprendizagem significativa. Mapas conceituais foram utilizados como ferramentas para a coleta e análise dos dados, acessando a estrutura cognitiva do sujeito da pesquisa, o que resultou em um mapeamento cognitivo que foi analisado qualitativamente e tratado estatisticamente por meio da análise de agrupamento hierárquico (AAH). Duas questões básicas foram investigadas: Como se encontram os conceitos de termologia de um estudante com ensino médio completo? Quais mudanças significativas podem se processar após ser ministrado curso estruturado segundo a abordagem ausubeliana? Os resultados mostraram uma grande concordância entre a análise quantitativa e qualitativa, indicando a grande diferença entre os resultados do pré-teste o do pós-teste e uma melhoria significativa na compreensão da termologia pelo estudante.
\end{abstract}

Palavras-chaves: Aprendizagem Significativa, Mapa Conceitual, "V" de Gowin, Estrutura Cognitiva, Análise de Agrupamento Hierárquico.

The work is based in the research of action utilized to investigate the process of meaningful learning. Conceptual maps were utilized as tools for collection and analysis of data, accessing the cognitive structure of the subject of research, what has resulted in a cognitive mapping that was analyzed qualitatively and with statistical treatment by means of Hierarchic Aggregation Analysis (HAA). Two basic questions were investigated: which are the concepts of terminology of a student that completed the high school? Which significant changes can occur after offering a course structured in accordance with the ausebelian approach? The results of this research demonstrated that there is a high concordance between the quantitative and qualitative analysis, indicating a large difference between the results of the pretest and posttest and a significant increment in the comprehension of the terminology by the student.

Key-words: Meaningful Learning, Conceptual Maps, "V" of Gowin, Cognitive Structure, Hierarchic Aggregation Analysis.

\section{INTRODUÇÃO}

Sobre a crise do ensino contemporâneo de ciências, Matthews [1] destaca a grande evasão de alunos e de professores das salas de aula bem como os elevados índices de analfabetismo científico, levando a Fundação Nacional Americana de Ciências a denunciar falhas nos programas dos cursos de graduação em ciências, matemática e tecnologia. Afirmando que estes não correspondem às necessidades nacionais. Este autor constata a existência de um mar de falta de significação, repleto de fórmulas e equações que são recitadas sem a real compreensão do que significam.

Para Moreira [2], este problema é decorrência de: falta de experimentos realizados pelos alunos, as salas superlotadas, programas excessivamente longos, o reduzido número de aulas, professores que não dominam o conteúdo ou não sabem passar, o grande número de problemas (questões) sobre o conteúdo apresentado e a enorme quantidade de fórmulas.

\footnotetext{
*Endereço Eletrônico: samfisica@yahoo.com.br

$\dagger$ Endereço Eletrônico: elder@uefs.br
}

Esses e outros fatores destacam a inadequação do ensino de física no Brasil, causada, segundo Moreira, por um fator fundamental:
"Não levar em conta, especificamente, aquilo que o aluno já sabe. Ou seja, não considerar que o aluno é um ser que aprende, usando para isso aquilo que já sabe o que já tem em sua mente." (Moreira, pg. 14) [2].

Para tratar esses problemas acima descritos, algumas técnicas de acesso à estrutura cognitiva, juntamente com a interpretação de Marco Antônio Moreira sobre a teoria ausubeliana, podem auxiliar o professor a fazer um "mapeamento" cognitivo a partir do grau de interação que o aluno atribui entre os conceitos e como estes se apresentam em sua mente. Com isso, o professor poderá otimizar o fluxo de informações durante o processo de ensino-aprendizagem.

Uma das técnicas de acesso à estrutura cognitiva, são os mapas conceituais, ferramentas que abrem caminho para as pesquisas longitudinais, que no dizer de Faria [3], objetivam a verificação de como os significados dos conceitos presentes nos estudantes mudam no tempo. Através dos mapas conceituais, o estudante pode compreender a sua própria dinâmica de aprendizagem, além de servir como mais uma estratégia de estudo, e para o professor, os mapas 
conceituais auxiliam na apresentação de itens curriculares e serve de instrumento para a avaliação de aprendizagem escolar.

É assim que o presente trabalho, que tem como objetivo comparar a estrutura cognitiva de um estudante antes e depois da aplicação da abordagem de ensino ausubeliana, pretende contribuir para a melhoria do ensino de física, através da apresentação de ferramentas pedagógicas que vão desde um modelo simplificado de plano de aula que possua as técnicas citadas acima até um referencial teórico que capacite o professor no momento da análise dos dados obtidos e do diagnóstico da anamnese realizada.

\section{REFERENCIAL TEÓRICO}

\section{A. Aprendizagem Significativa}

A idéia central da teoria ausubeliana, usada como referencial neste trabalho, está baseada no exame da dinâmica da estrutura cognitiva dos indivíduos, para então poder aplicar o processo de ensino e tentar observar alguma aprendizagem associada. A não arbitrariedade, juntamente com a não literalidade, aplicadas sob qualquer aspecto à estrutura cognitiva é a característica principal da aprendizagem significativa.

Estrutura cognitiva, segundo Faria [3], é definida como mecanismos de inteligência para lidar com as idéias. A partir dessa definição, pode-se notar que o processo cognitivo onde se inclui a memória do ser humano é essencialmente dinâmico e conceitual, e sempre haverá a possibilidade de utilizar elementos mentais preexistentes nessa complexidade descrita para estabelecer os devidos vínculos com os novos signos ou proposições apresentados durante o ato de ensinar.

Para esse modelo, o estudante é o responsável pelos significados idiossincráticos que cada conceito deve receber. E cada elemento mental responsável por esses vínculos, foi denominado por David Ausubel de subsumptiom ou subsunçor na tentativa de trazê-la ao domínio da língua portuguesa.

Outro aspecto é o que se refere à retenção das informações no indivíduo e Moreira [2] destaca:

\begin{abstract}
"Ausubel entende o armazenamento de informações na mente como sendo altamente organizado, formando uma espécie de hierarquia conceitual na qual, elementos mais específicos de conhecimento são ligados (e assimilados por) a conceitos, idéias, proposições mais gerais e inclusivas". (Moreira, pg. 21) [2].
\end{abstract}

Quando os subsunçores presentes na estrutura cognitiva de cada indivíduo são identificados pelo professor, inicia-se a instrução propriamente dita. O ponto de partida é a hierarquia conceitual, onde o assunto deverá ser trabalhado dos conceitos mais inclusivos e gerais, para os menos inclusivos. Além disso, Moreira e Peduzzi [8] destacaram a existência de outro processo baseado em "Explorar explicitamente as relações entre fenômenos e conceitos, apontando diferenças e similaridades entre eles, e fazer freqüentes referências aos aspectos gerais." (Moreira e Peduzzi, pg. 389) [8].
O primeiro passo é saber se o material didático que o professor utiliza é potencialmente significativo, ou seja, capaz de ser incorporado pela estrutura cognitiva do aprendiz, em outras palavras, se existe subsunçores que permitem a ocorrência da aprendizagem do conteúdo apresentado. Ausubel destaca os três tipos de aprendizagem significativa: representacional "É o tipo mais básico de aprendizagem significativa, do qual os demais dependem. Envolve a atribuição de significados a determinados símbolos (tipicamente palavras), isto é, a identificação, em significado, de símbolos com seus referentes (objetos, eventos, conceitos). Os símbolos passam a significar, para o indivíduo, aquilo que seus referentes significam"; conceitual "É de certa forma, uma aprendizagem representacional, pois conceitos são também representados por símbolos particulares, porém, são genéricos ou categóricos, representam abstrações dos atributos essenciais dos referentes, i.e., representam regularidades em eventos ou objetos"; proposicional "Contrariamente à aprendizagem representacional, a tarefa não é aprender significativamente o que palavras isoladas ou combinações representam, mas sim, aprender o significado de idéias em forma de proposição." (Moreira, pg. 157) [2].

$\mathrm{Na}$ aprendizagem significativa representacional, o indivíduo ainda não possui os subsunçores necessários para "ancorar" as novas idéias, mas nos outros dois tipos esse novo conceito pode se relacionar com o que havia anteriormente no estudante, havendo três formas: Superordenada, subordinada e combinatória. Moreira [2] destaca que a aprendizagem superordenada ocorre quando um conceito ou proposição potencialmente significativo é mais geral e inclusivo do que as idéias ou conceitos já estabelecidos na estrutura cognitiva. A compreensão do princípio da conservação de energia pode ser tratada como uma superordenação. Isto pode ser exemplificado a partir da afirmação: "a energia total de um sistema antes e depois de uma transformação sempre se conserva". Depois de muitos exemplos relativos a esse raciocínio envolvendo diferentes modalidades de energia, o estudante chega ao conceito de conservação de energia de forma geral, encarando os exemplos como casos particulares.

$\mathrm{Na}$ aprendizagem subordinada, para a nova informação adquirir significado, precisa interagir com os subsunçores. Esta forma de aprendizagem está subdividida em dois tipos: derivativa e correlativa.

Segundo Moreira [2], a aprendizagem subordinada derivativa acontece "Quando o material aprendido é entendido como um exemplo específico de um conceito já estabelecido na estrutura cognitiva, ou é apenas corroborante ou ilustrativo de uma proposição mais geral previamente aprendida." (Moreira, pg. 42) [2].

Já na aprendizagem subordinada correlativa, Moreira [2] conclui que esta se inicia quando o "Novo material é aprendido como uma extensão, elaboração modificação ou qualificação de conceitos ou proposições previamente aprendidos." (Moreira, pg. 43) [2].

A aprendizagem combinatória ocorre quando se trata de proposições ou conceitos que guardam relação de subordinação ou superordenação com o conteúdo amplo, inclusivo, existente na estrutura cognitiva, não podendo ser assimilados por conceitos e proposições já estabelecidos, nem assimilá-los. Moreira [2] caracteriza esse tipo de aprendizagem como "Combinações de idéias previamente aprendidas que podem ser relacionadas de maneira não arbitrária, a um "fundo amplo" de conteúdo, "relevante de uma maneira 
geral" com esse conteúdo como um todo." (Moreira, pg. 45) [2].

A compreensão equivalência entre massa e energia, é um exemplo de aprendizagem correlativa. Na ausência de subsunçores, é proposto uma solução a partir da aplicação de organizadores prévios "Que são materiais introdutórios, apresentados antes do próprio material a ser aprendido, porém em um nível mais alto de abstração, generalização $e$ inclusividade do que esse matérial." (Moreira, pg. 30) [2].

Enquanto não houver possibilidade de aplicar organizadores prévios, utilizamos a aprendizagem mecânica, caracterizada por Moreira como um estágio preparatório, onde "Novas informações são aprendidas praticamente sem interagir com conceitos relevantes existentes na estrutura cognitiva e pouco ou nada contribuindo para a sua elaboração e diferenciação." (Moreira, pg. 22) [2].

Após a aplicação dos organizadores prévios, examina-se a possibilidade de criar o subsunçor através do processo de assimilação, que ocorre na aprendizagem significativa, entre o novo material a ser aprendido e a estrutura cognitiva existente, contribuindo para a diferenciação dessa estrutura. Enquanto o processo de assimilação não for possível, utilizase uma aprendizagem heurística, onde o conteúdo principal a ser aprendido deve ser descoberto pelo aprendiz [2].

Para Ausubel, quando toda essa sequiência de passos relacionados com a formação do subsunçor for concluída, a dinâmica cognitiva do indivíduo irá escolher o tipo de aprendizagem significativa capaz de se adequar ao conceito apresentado, iniciando-se o processo contínuo de diferenciação progressiva, reconciliação integrativa e assimilação.

\section{B. Mapas Conceituais}

Levy [5]) justifica o uso dos mapas conceituais a partir do seguinte raciocínio: "Entendemos que uma aprendizagem verdadeira implica a construção do conhecimento por parte de quem aprende. Essa construção se processa a partir da interação social, num contexto mediado por ferramentas sócio-culturais dentro das quais a comunicação verbal tem papel preponderante."

As ferramentas sócio-culturais às quais a autora se refere, são as palavras, símbolos que possuem significados, passando a representar para o indivíduo aquilo que os seus referentes (objetos, eventos, conceitos) significam. Mapas conceituais "são esquemas gráficos que permitem representar a estrutura básica de partes do conhecimento sistematizado, representado pela rede de conceitos e proposições relevantes desse conhecimento." (Faria, pg. 1) [3].

Para a elaboração dos mapas conceituais, Faria [3] explicita a importância em separar os itens relevantes que farão parte do mapa, e isto deve ocorrer seguindo a teoria de Ausubel, selecionando os conceitos e proposições unificadoras de uma dada disciplina que possuam maior poder explicativo, caráter de inclusividade, possibilidade de generalização e de relacionamento com o conteúdo do assunto daquela disciplina. Além disso, o conteúdo deve ser organizado segundo os princípios ausubelianos da diferenciação progressiva e reconciliação integrativa como podemos ver abaixo:

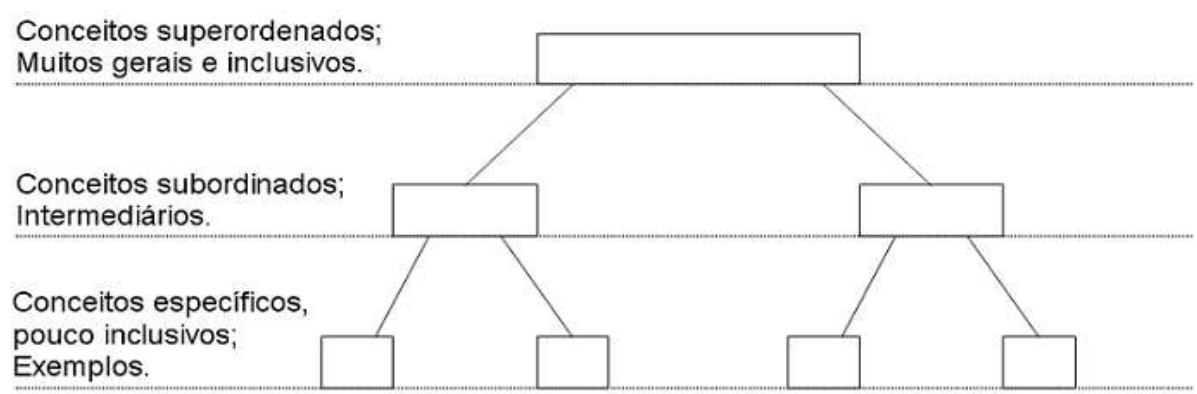

Para o presente trabalho, os mapas conceituais foram utilizados como recurso instrucional e cartográfico como destaca Faria [3]: "Os mapas conceituais podem ser concebidos também como instrumento para cartografar o conjunto de idéias aprendidas em uma área específica, por alunos ou por sujeitos de uma pesquisa educacional". (Faria, cap. XIV). Quanto às possíveis desvantagens do uso dos mapas conceituais como recurso instrucional, Moreira [2] destaca:

"Se o mapa não tiver significado para os alunos eles podem encará-lo apenas como algo mais a ser memorizado;

Os mapas podem ser muito complexos ou confusos e dificultar a aprendizagem e retenção ao invés de facilitá-las;

A habilidade dos alunos para construir suas próprias hierarquias conceituais pode ficar inibida em função do fato de que já receberam prontas as estruturas propostas pelo professor (segundo sua própria percepção e preferência)" (Moreira, pg. 83) [2].

Moreira [2] explica que algumas dessas desvantagens podem ser contornadas mostrando ao estudante qual é a finalidade do mapa e que ele pode ser construído de várias maneiras. Já o mapa do professor, este deve ser feito com o máximo de clareza e completicidade.

\section{PESQUISA QUALITATIVA E QUANTITATIVA}

A pesquisa educacional é influenciada por duas visões de mundo, a visão de caráter quantitativo (realista - objetiva) e a visão de caráter qualitativo (idealista - subjetivista). A questão fundamental está em discutir se há incompatibilidade ou complementaridade entre esses dois paradigmas. 
Uma possível solução para esse impasse seria admitir que qualquer esquema conceitual, teoria ou hipótese pressupõe crenças qualitativas substantivas que exerçam um papel essencial na fase das inferências ou conclusões científicas [6], definindo bem a existência de um elo de ligação entre esses dois aspectos metodológicos. E por esse motivo foi adotado nesse trabalho o caráter da complementaridade como um fator de riqueza metodológica, capaz de garantir, através da convergência dos resultados obtidos pelas diferentes análises, um maior teor de confiabilidade para a pesquisa. Por essa razão foi adotado como eixo central do trabalho o "V" epistemológico de Gowin, ferramenta capaz de unir esses dois gêneros de pesquisa através de uma única estrutura epistemológica.

\section{IV. "V" EPISTEMOLÓGICO DE GOWIN}

O "V" Epistemológico de Gowin é definido por Faria [3] como "Um instrumento heurístico organizado em torno da figura de um " $V$ ", que permite um mapeamento mais completo de uma determinada fonte de conhecimento do que os mapas conceituais" (Faria, pg. 31) [3]. Este instrumento heurístico segundo Moreira [7], propõe uma investigação da natureza do conhecimento e como ele é produzido. Isto só poderá ser analisado considerando os dois grupos de estrutura dinâmica visualizados, o grupo do domínio conceitual e o grupo do domínio Metodológico.

O primeiro é composto de filosofias subjacentes a teorias que contêm princípios e leis que são generalizações de relações entre conceitos que se referem as regularidades em eventos. O segundo é composto de asserções de valor sobre asserções de conhecimento que resultam do procedimento experimental que é conseqüência da análise e interpretações de dados provenientes das transformações das medidas obtidas observacionalmente, destacando que a gênese desse processo está nos eventos analisados.

Os dois grupos se relacionam a partir das questões básicas sobre eventos, na busca dos conceitos-chave relacionados, iniciando uma observação sucedida de medidas e transformações de fatos, as quais deverão ser interpretadas com o auxílio dos princípios e leis que governam o fenômeno. É assim que nasce uma teoria. Esta desenvolve asserções de conhecimento e através das suas filosofias subjacentes produzem as asserções de valor que implicam em respostas às questões éticas e pragmáticas.

\section{METODOLOGIA}

A abordagem ausubeliana foi escolhida pelo seu grande poder adaptativo, capaz de acompanhar as diferentes configurações assumidas pelas estruturas conceituais dos estudantes. Então, para tratar de uma investigação utilizando essa abordagem, um dos caminhos metodológicos que mais se aproxima desse dinamismo, é o do tipo pesquisa ação. Essa pesquisa foi orientada segundo o caráter metodológico do "V" Epistemológico Heurístico de Gowin, que propõe o início da investigação científica a partir de questões básicas. As questões básicas inicialmente propostas têm seu foco na possibilidade de averiguar como se encontram os conceitos de termologia de certo estudante que possui o ensino médio completo e freqüenta um cursinho de pré-vestibular há seis meses. Após o resultado dessa investigação, será aplicado para o estudante, um curso segundo a abordagem ausubeliana através da interpretação de Marco Antônio Moreira, e então será analisado o resultado dessa intervenção.

Foi escolhido um ensino individualizado devido à existência de resultados que indicam que o desempenho da abordagem ausubeliana quando aplicada em um único estudante é acentuadamente melhor do que no ensino em massa, sendo tal hipótese citada na literatura por [8] em um trabalho a respeito da influência da organização do conteúdo sobre a aprendizagem cognitiva do aluno:
"No estudo feito por Santos, onde foi usada ins- trução individualizada, a modificação na estru- tura cognitiva do grupo experimental, quanto ao seu aspecto estrutural, foi mais relevante do que a do grupo de controle. No entanto, Lima, que para o mesmo conteúdo envolvido no estudo de Santos usou um sistema de ensino tradicional, não obteve diferenças significativas no que se refere a rendimento e mapeamento cognitivo. Portanto parece haver evidências indicando que uma abordagem ausubeliana se torna mais efe- tiva quando levada a efeito juntamente com um sistema de ensino individual" (Moreira e Pe- duzzi, pg. 402) [4].

[8] cita outro argumento, baseado na idéia de que no ensino em massa, o professor leva em conta um hipotético estudante médio, perdendo informações relativas aos aspectos individuais e segue adiante na apresentação do conteúdo sem saber se o estudante assimilou os conceitos relevantes precedentes. Outro ponto fundamental é questionar qual é a validade dos "subsunçores médios" referentes ao estudante médio, se estes são capazes de cumprir seu papel durante a instrução pelo método ausubeliano.

Para possibilitar a investigação das questões básicas, foi criado um evento apropriado. Iniciado na aplicação de um pré-teste: Construção de um mapa conceitual pelo estudante contendo os principais conceitos da termologia ministrada no ensino médio, sucedido de um teste de proposições conceituais de termologia e um opinário.

Após o pré-teste esse estudante assistiu a um curso de termologia seguindo o método ausubeliano, cuja duração foi de quinze horas. Ao final do curso o pós-teste que é idêntico ao pré-teste, foi aplicado. Durante a análise dos dados obtidos a partir dos mapas conceituais, foram utilizados os recursos do mapeamento cognitivo, através da análise de agrupamento hierárquico associados ao tratamento qualitativo, baseado na teoria ausubeliana.

\section{ANÁLISE DE DADOS}

O trabalho investigativo foi iniciado através das seguintes questões básicas:

1- Como se encontram os conceitos de termologia de certo estudante que possui o ensino médio completo e freqüenta um cursinho de pré-vestibular há seis meses?

2- Após o resultado da questão anterior, e aplicando um curso seguindo a abordagem ausubeliana através de Marco Antônio Moreira, qual será o resultado dessa intervenção? 
Para responder a primeira pergunta, foram dadas ao estudante etiquetas contendo os seguintes conceitos: energia térmica, irradiação, energia interna, condução, calor, convecção, moléculas, $1^{\text {a }}$ lei da termodinâmica, lei zero, dilatação ou contração, trabalho, temperatura, mudança de fase, calor latente, entropia, calor sensível, líquido, sólido, gasoso, desordem, rendimento, ciclo de Carnot, transformações reversíveis, máquinas térmicas, volume, pressão, escala termométrica, variável de estado, transformações irreversíveis e fluxo de calor. Então, solicitou-se ao estudante que desenvolvesse um mapa conceitual.

Através desse mapa foi feita uma matriz de distância cujos elementos são o número de linhas que ligam os conceitos entre si. Essa matriz foi submetida à análise de agrupamento. Para tal procedimento, foi escolhida a (AAH) análise de agrupamento hierárquico, utilizando distância euclidiana e os seguintes algoritmos: Média de grupo ( $U n$ weighted pair-group average ou UPGMA), de ligação simples e completa. O UPGMA relaciona os grupos a partir das distâncias médias, formando grupos razoavelmente bem resolvidos, apresentando uma relação cofenética alta entre a matriz original e o dendrograma. Já o algoritmo de ligação simples, forma grupos por meio da menor distância de ligação dos conceitos par a par, por isso tende a gerar um encadeamento dos dados devido à correlação da matriz original com a matriz do dendrograma, partindo do par conceitual mais similar e unindo os conceitos que possuem os menores números de ligações. Destacando por último, o algoritmo de ligação completa que relaciona os grupos através do maior número de ligações.

Para efetuar os cálculos foi utilizado o software Statistica 5.5 versão para Windows [9]. Escolhe-se a opção "cluster analysis" que abre uma caixa de diálogo com uma nova opção, "joining tree clustering", onde é realizada toda a análise.

A consistência dos resultados foi examinada através da comparação dos gráficos obtidos para cada algoritmo, onde qualquer grande discrepância entre eles poderá reduzir o grau de confiabilidade dos dados.

Os instrumentos utilizados para auxiliar na análise qualitativa do mapa conceitual foram: o teste de proposição conceitual e um organizador prévio. O exame da estrutura cognitiva foi iniciado com a aplicação de um organizador prévio, instrumento responsável pela detecção e disponibilização dos subsunçores presentes na mente do estudante. Sua estrutura nesse caso foi composta de figuras do cotidiano enumeradas e que explicitam fenômenos estudados pela termologia.

Após a aplicação do organizador prévio das figuras apresentadas, o estudante listou em um papel os seguintes subsunçores de termologia: Temperatura, calor, energia, trabalho, pressão, dilatação, volume e molécula. Esse processo deve ser espontâneo, sem consultas, utilizando somente a memória.

Baseando-se nessa lista, foram destacados os conceitoschave: Molécula $(M)$, energia interna $(U)$, dilatação $(D)$, trabalho $(\mathrm{W})$, desordem $(D E)$, rendimento $(R)$, volume $(V)$, pressão $(P)$, calor $(\mathrm{Q})$, temperatura $(T)$, entropia $(S)$ e primeira lei $(P L)$.

O segundo passo foi a construção do mapa conceitual. Terminada essa etapa, o estudante respondeu um teste de proposição conceitual cuja estrutura é composta de frases descrevendo a relação entre dois conceitos, com a qual o estudante deve concordar ou discordar. Finalizando o processo, o estudante respondeu a um opinário.
Todo esse procedimento foi repetido após o tratamento com o método ausubeliano e finalizado com a aplicação de um novo opinário, destacando que as asserções que respondem à segunda questão básica, foram retiradas da comparação entre os resultados obtidos pelo pré-teste e pósteste.

\section{O PROCESSO DA INSTRUÇÃO}

Atualmente nas escolas, esse conteúdo é ministrado com a carga horária de aproximadamente, 16h. Por isso utilizamos $15 \mathrm{~h}$ de curso, distribuída ao longo de cinco dias e que determinou a confecção de cinco planos de aula. Inicialmente, o estudante recebeu material contendo um pequeno quadro histórico com alguns acontecimentos da física organizados cronologicamente, apostilas que explicam a estrutura da física, mapa conceitual dos principais conceitos físicos, mapa conceitual de termologia que irá orientar a seqüência do conteúdo e uma lista geral de exercícios de termologia.

Para a construção do material foram consultados os seguintes autores de livros de física voltados para o ensino médio: Gaspar [10]-[13], Ramalho et al. [14] e Ferreira [15]. Também foram consultadas obras de autores como Alonso e Finn [16], Cunha [17] e Nussenzveig [18] como principais suportes teóricos.

\section{RESULTADOS OU TRANSFORMAÇÕES}

\section{A. Antes da Aplicação da Abordagem Ausubeliana}

O estudante afirmou ter muita dificuldade em compreender a física, pois achava que esta ciência possuía um conteúdo muito complexo e a maioria dos professores não estavam preparados para ensiná-la. Através do organizador prévio, foram listados em um papel os seguintes subsunçores de termologia: temperatura, calor, energia, trabalho, pressão, dilatação, ciclo, volume e molécula.

O teste de proposições conceituais indicou que o estudante confundia os conceito de calor e temperatura, não relacionava temperatura com energia interna e desconhecia o significado físico do conceito de entropia.

Através da análise qualitativa do mapa conceitual (antes da instrução), alguns pares conceituais importantes e mais próximos puderam ser destacados: $\{S, P L\},\{R, P\}$, $\{D, Q\},\{M, D\}$. Esses dados indicam os pares conceituais que estão mais relacionados entre si na mente do estudante (conceitos ligados por uma única linha). Já os pares pouco relacionados mais importantes são: $\{M, T\},\{Q, T\}$, $\{T, D\},\{W, R\},\{U, Q\},\{U, W\},\{D, Q\}$ (conceitos ligados por mais linhas).

$\mathrm{O}$ resultado obtido a partir da $(\mathrm{AAH})$ com os algoritmos de distância de ligação simples, distância de ligação completa e UPGMA, não mostraram diferenças significativas na organização dos dados, comprovando a consistência dos mesmos. Então foi utilizado o algoritmo UPGMA, pois gera os maiores valores de correlação da matriz original 
com a matriz do dendrograma, indicando através do gráfico (anexo 1), os conceitos mais relacionados: $\{Q, W\},\{R, P\}$, $\{D, U\},\{T, P L\},\{M, D\}$ (ordem decrescente). Já os pares pouco relacionados mais importantes são: $\{M, P\},\{P, U\}$, $4\{V, D\},\{D, Q\}$ (ordem decrescente).

\section{B. Depois da Aplicação da Abordagem Ausubeliana}

O estudante considerou que a física pode ser uma matéria agradável de ser estudada, não só para o vestibular, mas para a vida e demonstrou grande aceitação em relação ao método ausubeliano afirmando sua capacidade em aumentar o rendimento no estudo.

O resultado do teste de proposições conceituais indicou que o estudante já não confunde mais calor e temperatura, os conceitos de energia interna e temperatura se aproximaram, o termo entropia ficou associado ao subsunçor desordem e o termo energia interna ao subsunçor energia.

Através da análise qualitativa do mapa conceitual (após a instrução), alguns pares conceituais importantes e mais próximos puderam ser destacados: $\{Q, U\},\{U, W\}$, $\{W, P\},\{W, V\},\{W, R\},\{M, T\},\{P L, Q\},\{P L, U\}$, $\{S, D E\}$. Esses dados indicam os pares conceituais que estão mais relacionados entre si na mente do estudante (conceitos ligados por uma única linha). Já os pares pouco relacionados mais importantes são: $\{T, W\},\{M, P\}$, $\{M, V\},\{M, D E\},\{M, R\},\{T, P\},\{T, V\}$. (conceitos ligados por mais linhas).

Foi utilizado novamente o algoritmo UPGMA, pois gera os maiores valores de correlação da matriz original com a matriz do dendrograma, indicando através do gráfico (apêndice), os conceitos mais relacionados: $\{V, P\}$, $\{P L, Q\},\{S, D E\},\{M, T\}$ (ordem decrescente). Já os pares pouco relacionados são: $M, P,\{M, V\},\{T, P\}$, $\{T, V\},\{M, R\}$ (ordem decrescente e maior grau), $\{T, W\}$, $\{M, D E\}$ (menor grau).

\section{CONSIDERAÇÕES FINAIS}

Antes da instrução o estudante parecia não possuir conhecimento da $1^{\mathrm{a}}$ lei da termodinâmica, entropia, rendimento, energia interna e trabalho. Após a instrução, os conceitos assumiram uma nova configuração na estrutura cog- nitiva do estudante, destacando uma considerável evolução conceitual.

No fluxograma da aprendizagem significativa da informação, está presente o processo de assimilação, ocorrido quando o estudante percebeu que a sua idéia sobre temperatura não conseguia explicar satisfatoriamente as questões apresentadas e que os novos atributos criteriais apresentados sobre o conceito faziam mais sentido do que o seu, pois estes possuíam significado lógico e psicológico. As únicas exceções foram os conceitos de $1^{\mathrm{a}}$ lei da termodinâmica, entropia, rendimento, energia interna e trabalho. O conceito de rendimento foi incorporado a estrutura cognitiva através do processo de subordinação derivativa, onde rendimento foi considerado menos geral e inclusivo do que trabalho. Os conceitos trabalho e energia interna sofreram o mesmo processo do conceito rendimento, porém o subsunçor responsável por ancorá-los, foi energia.

Com o conceito $1^{\mathrm{a}}$ lei da termodinâmica, o processo já foi diferente, este foi mais geral e inclusivo do que os subsunçores presentes na estrutura cognitiva do estudante, traduzindo em uma aprendizagem superordenada.

As conseqüências teóricas desse experimento ou asserções de conhecimento podem ser destacadas a partir da eficiência dos mapas conceituais e testes de proposições conceituais, que se apresentaram como ferramentas capazes de dar ao professor informações sobre o tipo de relacionamento que o aluno estabelece entre os conceitos. Além da importância de organizar a instrução seguindo os princípios da diferenciação progressiva e reconciliação integrativa.

Importantes asserções de valor podem ser obtidas através dos resultados. A primeira foi a grande receptividade por parte do estudante em relação ao método ausubeliano. A segunda está na motivação gerada no estudante e no desenvolvimento da percepção da sua própria dinâmica de aprendizagem.

Outro ponto importante foi a grande concordância entre a análise qualitativa e quantitativa. Durante todo o trabalho de investigação, o aspecto idiossincrático do estudante sempre foi de muita relevância no quesito aprender, e foi a partir dele que nasciam os paradigmas que alimentavam os seus "modelos científicos pessoais" concernentes aos seus modelos mentais, enriquecidos pelas novas idéias que lhes eram apresentadas. 
GRÁFICOS DA (AAH) (ANTES DA APLICAÇÃO DO MÉTODO)

Diagrama de árvore para 12 Variáveis (MAPA 01)

Ligação simples

Dișância euclidiana

Molécula (M)

Energia interna (U)

Dilataçấo (D)

Trabalho (W)

Desordern (DE)

Rendimento (R)

Volume (V)

Pressẫo (P)

Quantidade de

calor (Q)

Temperatura (T)

Entropia (S)

Primeira lei (PL)

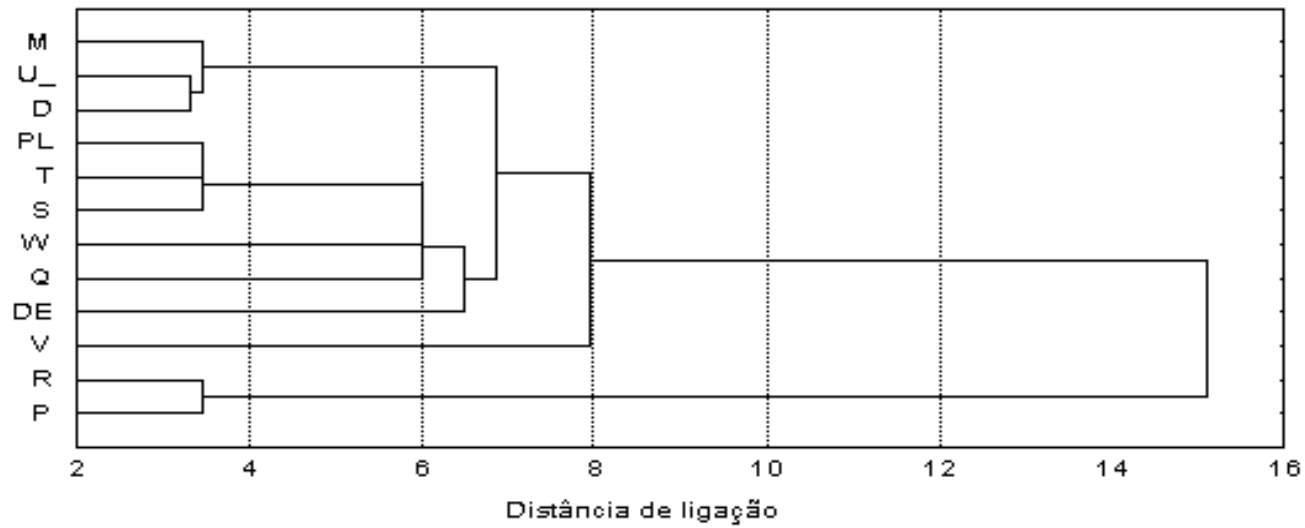

Diagrama de árvore para 12 Variáveis (MAPA 01)

Ligą̧̃o completa

Distância euclidiana

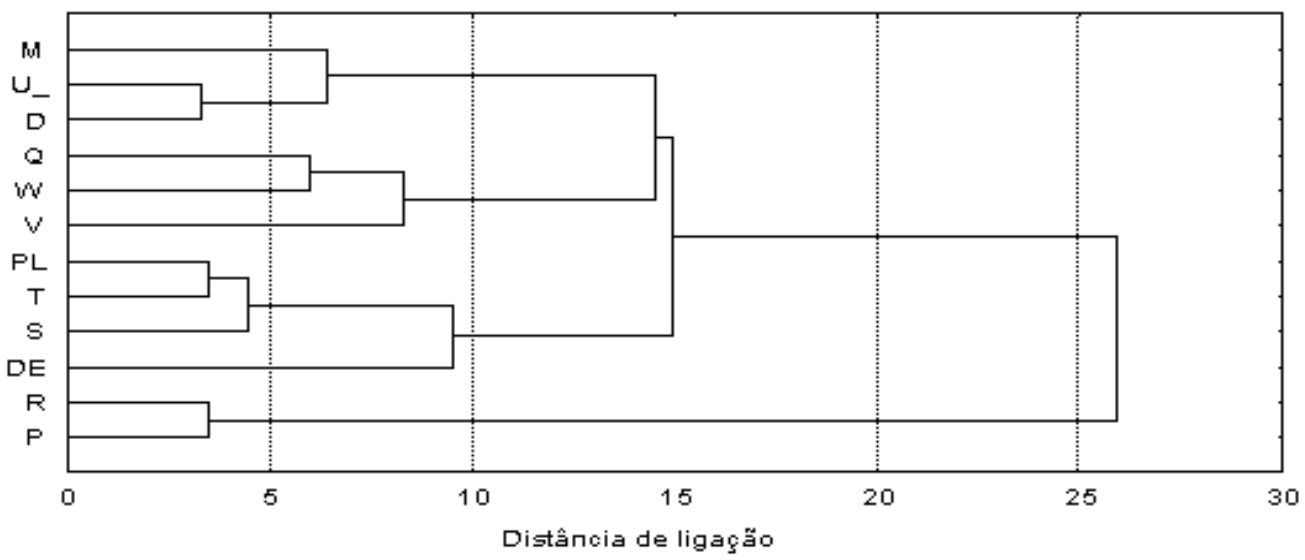

Diagrama de árvore para 12 Variáveis (MAPA 01)

Média de grupo

Distância euclidiana

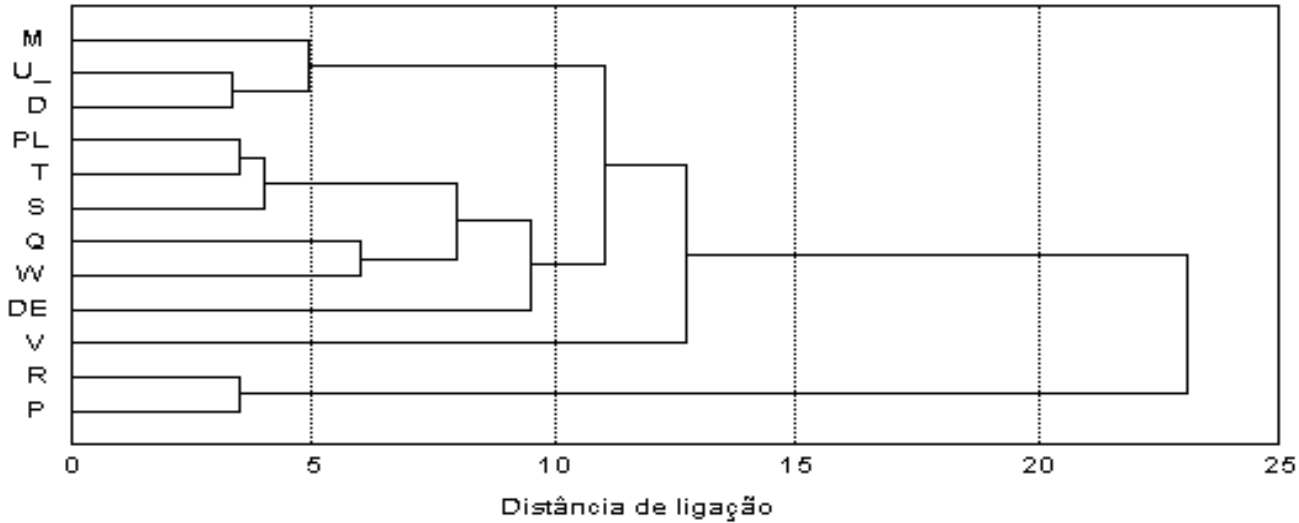




\section{GRÁFICOS DA (AAH) (DEP OIS DA APLICAÇÃO DO MÉTODO)}
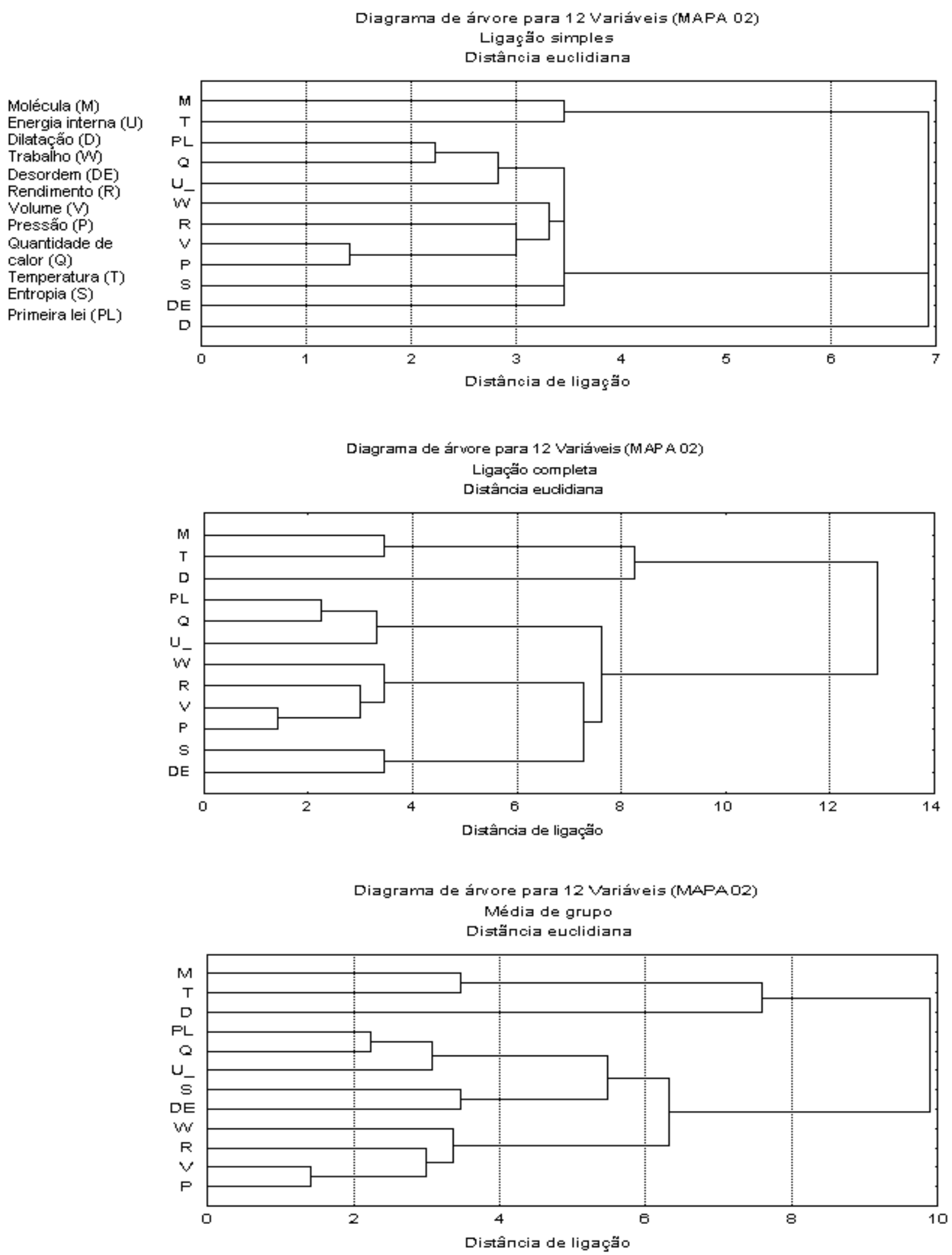

[1] M.R. Matthews; História e filosofia da ciência: a tendência atual de reaproximação, Cad. Catarinense de Ensino de Fís. Santa Catarina, 12, (3) 164 (1995).

[2] M.A Moreira; Uma abordagem cognitivista ao ensino da física, $1^{\mathrm{a}}$ ed. Porto Alegre, Ed. da Universidade, UFRGS, (1983).

[3] W. Faria; Mapas conceituais: Aplicações ao ensino, currículo e avaliação, $1^{\mathrm{a}}$ ed. São Paulo, EPU, (1995). 
(Temas básicos de educação e ensino).

[4] M.A Moreira; Pesquisa em ensino: Aspectos metodológicos e referenciais teóricos à luz do vê epistemológico de Gowin, $1^{a}$ ed. São Paulo, EPU, (1990).

[5] M.I.C. Levy; A Questão da Representação no Ensino de Ciências, (1999). Disponível em: http://www.sf.dfis.furg.br/mea/remea/anais3/artigo14.htm.

[6] J.C.F. Santos, S.S. Gamboa; Pesquisa educacional: Quantidade-qualidade, $3^{\mathrm{a}}$ ed. São Paulo, Cortez (2000).

[7] M.A Moreira; Aprendizagem significativa: um conceito subjacente. In: Encontro Internacional sobre Aprendizagem significativa, Espanha: Burgos, (1997).

[8] M.A Moreira, S.Peduzzi; Influência da organização do conteúdo sobre a aprendizagem cognitiva do aluno: Um estudo comparativo, Rev. Bras. Ens. Fis. 12 (2) (1982).

[9] SCATSOFT, INC. STATISTICA for Windows (computer program manual), Tulsa, SatSoft Inc. (1995).

[10] A. Gaspar; Física: Mecânica. Manual do professor, $1^{\mathrm{a}}$ ed. São Paulo: Ed. Ática. (2000).

[11] A. Gaspar; Física: Mecânica, $1^{\mathrm{a}}$ ed. São Paulo: Ed. Ática. (2000).

[12] A. Gaspar; Física: Ondas, óptica e termodinâmica. Manual do professor, $1^{\mathrm{a}}$ ed. São Paulo: Ed. Ática. (2000).
[13] A. Gaspar; Fúsica: Ondas, óptica e termodinâmica. $1^{\mathrm{a}}$ ed. São Paulo: Ed. Ática. (2000).

[14] F.J. Ramalho, N.G Ferrato, P.A.S. Toledo; Os fundamentos da física: Termologia, Óptica e Ondas, $7^{\mathrm{a}}$ ed. São Paulo, Moderna (1999).

[15] M.S. Ferreira; 1000 questões de física, $1^{\mathrm{a}}$ ed. Paraíba: Marcos Ferreira da Silva, (2001).

[16] M. Alonso, E.J. Finn; Física um curso universitário, Tradução de Giorgio Moscati. 2. ed. São Paulo: Edgard Blücher (1972).

[17] J.A. Cunha; Filosofia: Iniciação a investigação filosófica, $1^{\text {a }}$ ed. São Paulo, Atual, (1992).

[18] H. M. Nussenzveig; Curso de Física Básica 2, 2a ed. São Paulo, Edgard Blücher (1981).

[19] S. Santana; Exame das Implicações da Abordagem Ausubeliana Interpretada por Marco Antônio Moreira, a Partir das Técnicas de Acesso à Estrutura Cognitiva: um Estudo de Caso, Trabalho de Conclusão de Curso (Licenciatura em Física) apresentado ao DFIS-UEFS, Feira de Santana (2005).

[20] Para maiores detalhes, consultar a referência Santana (2005). 